Trataremos de ubicar el concepto de patrimonio dentro del más contemporáneo de modernidad, y repensarlo a la luz de los acontecimientos de cambio que nos tocan vivir en este final del milenio.

El conjunto de bienes materiales e inmateriales que heredamos merecen investigarse, valorarse y ser conservados como mecanismo a la vez realista y simbólico de la defensa de nuestra identidad, y como explicitación del concepto de permanencia que el hombre necesita para trascender y encontrar así la clave de su sentido de la vida.

La modernidad no es propiamente una alternativa cultural frente a otras que pudieran darse en el pasado, sino una forma de organización social necesitada de su total universalización o, mejor dicho, mundialización.

Las culturas particulares no tienen derecho, en esta lógica de la modernización, a permanecer ancladas en sus propias tradiciones. Este es un lujo que contradice la vida cotidiana de la modernidad, que se define a sí misma en función de su universalidad.

Tensando el hilo de estas reflexiones, todo aquel patrimonio no universal, toda manifestación particularista de una cultura pasaría a convertirse en folklore, último plano permitido por la modernidad que, asociado al turismo, se ha convertido en una industria rentable de las economías desarrolladas. Visto así, el folklore no es más que una mascarada de particularismo y de identidad cultural. Se trata de una identidad trivializada.

El universalismo de la modernidad sustituye toda definición cultural de los valores por una definición funcional.

A poco que observamos los cambios de hoy afirmamos con el filósofo Leszek Kolakowski que muchas predicciones construidas racionalmente en el siglo XIX, están más equivocadas que las llamadas ilusiones que intentaban disipar. Tanto los liberales seculares como los socialistas esperaban que las pasiones nacionales, o tribales, desaparecieran gradualmente y que los medios de comunicación mejorados y una más correcta comprensión científica del universo ocupara su lugar. Pero resultó no ser así.

La necesidad de pertenecer a un grupo es más fuerte que nunca. Los conflictos nacionalistas, al contrario de desaparecer, parecen acrecentarse.

Una parte del mundo, especialmente en el desarrollado, se enfrenta a una forma de organización social que necesita universalizarse, pero cuya medida de universalización es el sometimiento de todos los particularismos culturales a la funcionalidad de las estructuras de intercambio.

Otra parte, menos desarrollada, quiere beneficiarse de la expansión moderna, pero no parece estar dis-

\title{
PATRIMONI0, BREVES REFLEXIONES EN TORNO AL FINAL DEL MILENIO
}

puesta a sacrificar su propia identidad particular. Un conjunto de culturas particulares, muchas de ellas internas al propio mundo desarrollado, ven el modelo actual de desarrollo como una amenaza a su propia sobrevivencia cultural, a pesar de que están dispuestas a asumir la racionalidad técnica de la producción mercantil.

El desempleo y sus secuelas, y la concentración en pocas empresas del excedente del incremento económico es lo contrario a lo que preconizaban los agentes modernizadores. El problema radica justamente en creer que el desafío de la modernización se resuelve en el plano de la modelística y, más aún, en la universalidad de los modelos.

No quisiéramos que se confundan los particularismos culturales con el nacionalismo. Schlegel sostenía que el amor al espíritu nacional deviene en necesidad de reintegrar todos los ordenamientos en los cuales aquel espíritu se ha realizado en su historia. Así se produce la sustracción de valores culturales particulares en aras de una supuesta identificación pueblo-Estado, de lo cual tiene sobradas pruebas la cultura andaluza.

Coincidimos con el ensayista argentino Juan José Sebreli cuando dice que los nacionalistas personalizan la tierra, la transforman en un sujeto del cual los hombres que la habitan son mero atributo; por eso los derechos individuales son subordinados a la soberanía nacional, "primero la Patria, después los Hombres" es una típica consigna nacionalista, pero la tierra y por extensión el Patrimonio, no tiene valor en sí, sino en función de los hombres que la habitan y la disfrutan. Por lo tanto debería desacralizarse y relativizarse el concepto de soberanía territorial, y absolutizarse en cambio los derechos individuales y de las minorías culturales.

Es absurdo seguir hablando de soberanía nacional en un mundo controlado hasta el milímetro por satélites o donde los ordenadores almacenan y procesan una enorme cantidad de información de los Estados o donde las noticias son transmitidas vía satélite al instante de un extremo al otro de la Tierra.

La crisis de valores es muy amplia. Fascismo y comunismo representaron una aparente y siniestra perfección del Estado ilustrado que siempre sabe más que sus ciudadanos. Coincidimos con Xavier

\author{
Marcelo Martín \\ Arquitecto
}

\section{¿Cómo reconciliar la legitimidad de modernidad frente a la realidad tradicional? ¿Qué valor le atribuimos al} Patrimonio desde la óptica del desarrollo o del subdesarrollo? 
Rubert de Ventós en que el Estado resulta de la mezcla explosiva de universalismos contrapuestos: el territorial romano y el ideológico o espiritual cristiano.

Tampoco sería propio admitir similitudes entre particularismos culturales y fundamentalismo. Volvamos a Rubert de Ventós. Cuando una sociedad es más prístina, cuando se ha construido sin materiales de aluvión, cuando el grado de solapamiento de factores como la ley o el territorio es mayor, cuando menos intensa ha sido la capacidad de modernización civil de sus infraestructuras y cuando, por el contrario, más intensa ha sido su estatificación, puede hablarse de un nivel de fundamentalismo máximo.

Fuera de nacionalismos y fundamentalismos parece que el Estado, en la medida que pueda resistir al chantaje económico a que lo someten las multinacionales, deberá empezar a solapar las diferentes calidades de soberanía que implican las regiones, las comarcas, las ciudades. En definitiva, dar lugar a esos reductos de memoria que son los pueblos que conforman un país.

Los profesionales del Patrimonio no pueden quedar al margen de esta toma de posición. Serían aún más graves que la ausencia de criterios sobre tutela, carecer de la visión de lo que la herencia cultural particular amenazada puede significar para la comunidad que sustenta su trabajo.

Es imprescindible estar atentos a manipulaciones de orden ideológico o político que pueden llevarse a cabo en nombre de una supuesta "recuperación de los valores nacionales o universales" en torno al Patrimonio heredado.

La insurrección armada protagonizada recientemente en Chiapas, México, por un colectivo campesino indígena nos plantea un motivo de reflexión acerca de la soberanía y la herencia cultural.

Bibliografía

Kolakowski, Leszek. Entrevista "El racionalismo se equivocó sobre la religión”, sección cultural Babelia, El País, 26 de marzo de 1994.

Morande, Pedro. Cultura y Modernización en América Latina,

Cuadernos del Instituto de Sociología Pontificia, Universidad Católica de Chile, Santiago de Chile, 1984.
En las antípodas de lo declarado por Octavio Paz sobre que "sería gravísimo conceder a las comunidades indígenas regímenes de autonomía que significasen la vigencia de dos leyes: la nacional y la tradicional", afirmamos que sería precisamente esta comprensión de soberanía lo esperanzador y novedoso para este intolerante final de milenio.

De no ser así, ¿cuál sería el concepto de Patrimonio que debería prevalecer frente a la justa reivindicación indigenista? No creemos que pueda establecerse una dicotomía ni una desvalorización, tanto de las tradiciones y pautas culturales de los campesinos como de los bienes, haciendas y cultura de los hacendados.

No creemos en una visión aséptica de la historia pero la valoración de los bienes culturales debería quedar al margen de los juicios de orden político-

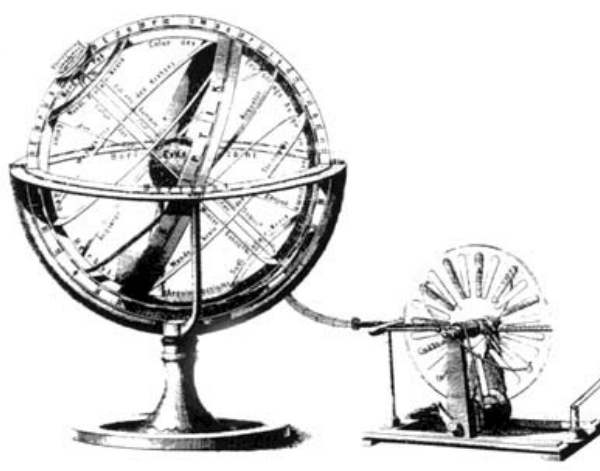

ideológicos, ya que de ellos se puede obtener en el futuro la información tanto de la injusticia como de la sabiduría de los pueblos.

No creemos en una supuesta imparcialidad histórica, la imparcialidad del concepto de patrimonio también puede esconder una fuerte dosis de hipocresía frente a la disparidad de los modelos culturales entre mayorías y minorías sociales.

Hipocresía manifiesta en la protección de un Patrimonio Universal dentro de particularidades culturales, paralelamente a la destrucción de sus tradiciones y pautas de desarrollo por la salvaje filosofía del neoliberalismo capitalista.

¿Cómo reconciliar la legitimidad de modernidad frente a la realidad tradicional? ¿Qué valor le atribuimos al Patrimonio desde la óptica del desarrollo o subdesarrollo?

Desde el núcleo más doliente de la crisis de valores de fin de siglo, la economía, surge el concepto de desarrollo sostenible. Este enfatiza el carácter dinámico del desarrollo y reconoce la existencia de conflictos y desequilibrios que son en sí mismos reflejo de situaciones cambiantes. Obliga a examinar dimensiones cuantitativas (crecimiento) como cualitativas (calidad de vida), desde la perspectiva de las condiciones que posibiliten un proceso conducente al mayor bienestar social de hoy, sin hipotecar el futuro de nuestras generaciones venideras. El concepto explícita la íntima, inevitable y mutua interdependencia entre sistema natural y desarrollo y reconoce la existencia de límites y conflictos.

La herencia cultural forma parte de ese equilibrio entre sistema natural y desarrollo. Los supuestos modernizadores por un lado y los fundamentalistas por otro acusan a las sociedades tradicionales de sustentar valores antimodernos o de no poseerlos. Como dijimos, la modernidad no es una alternativa cultural particular, sino un intento de secularizar todos los valores en la funcionalidad 


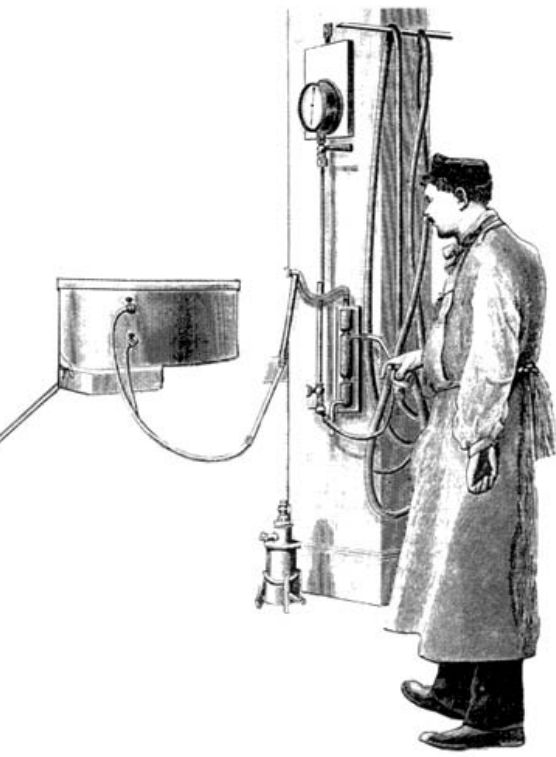

de las estructuras. En rigor todo valor que se afirme a sí mismo independientemente de la "eficiencia" del sistema es considerado un obstáculo al desarrollo.

Desde un punto de vista del equilibrio y afirmación de valores culturales particulares el Patrimonio no solo no es un obstáculo sino un vehículo de desarrollo sostenible. Afirmación que sustentamos desde la obligación que tenemos como profesionales progresistas de recordar las virtudes que se sacrifican con la opción social que sustentamos.

El Patrimonio materializa la tensión entre pasado y futuro y dicha tensión está destinada a pervivir con nosotros por siempre.

Cuando afirmamos que la modernidad seculariza los valores creemos que dicha secularización lleva implícita la pérdida del sentido sagrado de las culturas.

Con la desaparición de lo sagrado, que impone límites a la perfección a la que aspira una sociedad surge, al decir del ya citado Kulakowski, una de las más peligrosas ilusiones de nuestra civilización: la ilusión de que no existen límites a los cambios que podemos emprender, y por ende, que tampoco existen límites a lo que queramos conservar

Todo parece ser factible ante los caprichos creativos de nuestra sociedad científico-técnica.

Considerarse totalmente libres de la herencia cultural es situarse en un vacío y, por tanto, desintegrarse. Dice Kulakowski, esta fe utópica en la capacidad autoinventiva del hombre, esta esperanza utópica de perfección ilimitada puede ser el instrumento de suicidio más eficaz que jamás haya inventado la cultura humana. No existen frenos morales al poder de la voluntad.

¿Le quedan todavía a las ciencias categorías conceptuales capaces de comprender los particularismos culturales?
La respuesta requiere de una reflexión crítica e histórica, rindiendo homenaje a los orígenes y a los acontecimientos fundacionales. Un final de milenio es una época adecuada, más que para el nihilismo, para la "tolerancia pluralista".

La utopía podría volver como tantos revivals de fin de siglo. Pero hay que tener tanto cuidado a la hora de "creer en una utopía verde como en una roja". Existe el peligro de hipotecar el futuro por un desarrollo presente como sacrificar este presente por alguna salvación lejana.

Hablamos de tolerancia pluralista como oposición a la tolerancia indiferente. La indiferencia es la forma principal de tolerancia en Occidente. A menudo nuestra actitud tolerante es poco más que falta de interés o incredulidad: somos tan indiferentes a nuestras propias creencias y tradiciones como a la de los demás.

¿Cuál será la clave que nos permita pensar en el Patrimonio desde una perspectiva multicultural tolerante e integradora?

Los particularismos culturales viajan por el mundo. Se establecen, hechas raíces en otros sitios, se integran, se oponen, resisten, modifican. Los mismos bienes muebles e inmuebles de un pueblo cobran nuevos significados frente a una inmigración con pautas culturales ligadas a un pasado que les fuera común.

Los valores y la moral deberían filtrarse en las categorías de pensamiento científico respecto de la herencia cultural. No se puede querer al musulmán en el huerto pero no en nuestros museos. No se puede aislar al hispanoamericano sin aislar nuestra propia historia lejana y reciente.

Los territorios ocupados en Israel y la ciudad de Jerusalén son un ejemplo del nuevo significado que pueden cobrar los bienes heredados y el peligro de la reinvención política de esos bienes en función del concepto de Estado.

Jerusalén sería el caso ideal para desarrollar un sistema tolerante e integrador de soberanía cultural en el cual podrían solaparse: el patrimonio individual de las personas (sus tradiciones, sus religiones), el patrimonio local (las iglesias, las sinagogas, las mezquitas), el patrimonio regional (la cultura mediterránea), el patrimonio nacional (leyes de protección del Estado de Israel) y el universal (la herencia histórica y material que comparten las tres grandes religiones monoteístas del mundo).

Alguien puede alegar sobre mi tendenciosa utopía. Otros, que es ya tradición y memoria histórica el enfrentamiento entre árabes y judíos. De esta forma construimos nuestra historia reciente y destruimos el patrimonio. El nuevo milenio exige una nueva actitud, pero eso es futuro y no historia.
Paz, Octavio.

Tiempo Nublado,

Sudamericana-Planeta

Buenos Aires, 1984.

Rubert de Ventós, Xavier.

El Laberinto de la

Hispanidad.

Nacionalismos, Espasa-

Calpe, Madrid 1994.

Sebreli, Juan José.

El Asedio a la

Modernidad, Editorial

Sudamericana, Buenos

Aires, 1991. 